\title{
LA INFLUENCIA DE STRAWINSKY EN MEXICO
}

$\mathbf{P} \mathbf{O}$

\section{VICENTE T. MENDOZA}

Por fin, tras cerca de veinte años de expectación, llegó a México Igor Strawinsky; $y$, como todos Jos acontecimientos aguardados con ansia, culminó plenamente, se realizó a la medida del deseo la esperanza y ésta fué compensada con largueza.

La juvebtud que le intuia, en el transcurso de estas dos décadas, maduró progresivamente y, no obstante ello, su sueño correspondió exactamente con
la realidad. El embrujamiento producido por la música del genio estuvo en perfecto acuerdo con el deseo largo tiempo acariciado.

Fué en 1921 cuando, en su viaje de regreso a México, Antonio Gómez Anda trajo entre sus papeles las partituras de "Petrouchka" y la "Consagra-
ción de la Primavera" y durante varias horas, en algunas ocasiones nos deHacia 1924, durante las luchas por "El Sonido Trece", el nombre de
Strawinsky y la influencia de su labor apareció como un señuelo, símbolo del ideal musical de este siglo; y aun tuvimas oportunidad de discutir, en compañia del autor del "Sonido Trece", la técnica Strawinskiana. 
A partir de esta fecha, durante el periodo que va hasta 1928, nuestras inquietudes musicales estuvieron siempre encauzadas hacia los tres luminares que por entonces marcaban la cima del arte: Debussy, Ravel y Strawinsky. Durante dicho período, de una aridez desconcertante en nuestro ambiente musical, carente por esos días de manifestaciones de verdadero relieve, aparecia ante nuestro azoro el "Pájaro de Fuego", que escuchábamos embelesados únicamente a través de discos fonográficos, y nos comprobaba su origen eslavo, maravillosamente concatenado con la Scherazada de su maestro Rinisky Korsakoff y la obra de los otros cuatro rusos cuyas impresiones nos fueron proporcionadas por las dos temporadas de ópera rusa que por entonces actuaha en México.

Hacia 1928, cuando la Orquesta Sinfónica de México principió a organizarse, bajo la dirección de Carlos Chávez, existía en México de una manera más persistente, el deséo imperioso de escuchar las obras de Strawinsky y la Directiva de la Sinfónica, en su plan de trabajo, lo incluyó desde un principio. Ya por esos dias fragmentos desglosados de sus obras sinfónicas, eran ejecutadas al piano por nuestros concertistas; la presencia en México del pianista argentino Héctor Ruiz Diaz, excitaba con sus ejecuciones al piano ntestra curiosidad.

Fué hasta 1930 cuando Carlos Chávez pudo incluir un programa completo dedicado a Strawinsky. En forma ascendente, en esa ocasión, escuchamos con verdadero deslumbramiento "El Canto de los Bateleros del Volga", "Los Fuegos de Artificio", la suite de "El Pájaro de Fuego" y la partitura completa de "Petrouchka" el viernes 14 de febrero, concierto memorable que descorrió como un velo, dándonos la impresión completa de la personalidad de Strawinsky.

De ahi para adelante un gran número de obras se nos ha ido mostrando, unas veces por el Coro del Conservatorio y otras por la Orquesta Sinfónica de México, en combinación con solistas. Asi hemos escuchado en 1931 las "Bodas"; en 1932, la Sinfonía de "Los Salmos"; en 1933, "La Suite número 2 para pequeña orquesta"; en 1934, el "Concierto para piano y orquesta", con la colaboración de Claudio Arrau; en 1935, "La Consagración de la Primavera", en 1937 el "Capricho para piano y orquesta", con la colaboración del pianista español Jesús Măría San Romá; en 1938, el "Apolo Musageta".

$Y$ sólo fué en este año de 1940 y debido a las gestiones hechas por Carlos Chávez, cuando nos cupo la suerte de que personalmente Igor Strawinsky visitara nuestra capital y dirigiera cuatro conciertos de la temporada de la Orquesta Sinfónica de México, ejecutando dos programas. En el primero dirigió la obertura de "Anacreonte", de Cherubini; la "Segunda Sinfonía en 
Do Menor" (Op. 17), de Tchaikowsky; el divertimiento de "El Beso del Hada" y una selección de la suite de ballet "Petrouchka". En el segundo programa dirigió el "Apolo Musageta", repitió el divertimiento del "Beso del Hada", dió a conocer el ballet "Juego de Baraja" y dirigió el "Pájaro de Fuego".

La trascenciencia que para los estudiosos de la música tiene la presencia de Igor Strawinsky en. México, dirigiendo estos conciertos, es fácil de presumir si se tiene en cuenta la avidez con que hemos seguido sus pasos durante el período que abarca esta nota. Unas veces examinando su ritmo, otras persiguiendo los modos ortodoxos en que concibe sus melodias, la naturaleza de éstas y su alcance estético. Otras, tratando de encontrar los elementos armónicos y contrapuntísticos con que reviste su producción, y en multitud de ocasiones tratando de hallar en la forma ballet que utiliza, los elementos indispensables para un desarrollo individual de la música de México.

Esto ha traido por consecuencia que nuestros jóvenes compositores, que se apegan demasiado a la letra muerta, incufran en imitaciones formulisticas ; que otros, que ahondan en los problemas de la instrumentación y el color orquestal, persigan las combinaciones sonoras que aparecen más claras y visibles en el "Pájaro de Fuego" y en "Petrouchka"; otros, persiguen los diseños con que recama su producción consiguiendo un sabor o un matiz determinados; y por último, muy pocos, se adentran en el espíritu rítmico, esencial en Strawinsky, $y$ traten de obtener verdaderos ballets.

la enorme ventaja que esto ha proporcionado a nuestros músicos es el estímulo que la verdadera obra de arte hace nacer en los individuos musicalmente dotados y que este entusiasmo se traduzca en obras tangibles que, no obstante las influencias señaladas, forman ya parte de un acervo musical nuestro que camina a pasos agigantados por un sendero amplio y recto que nos conducirá seguramente a la cima de nuestras aspiraciones, que son cristalizar 